12,16

\title{
Зависимость энергии эмиссионных молекулярных орбиталей в коротких открытых углеродных нанотрубках от электрического поля
}

\author{
(C) О.Б. Томилин ${ }^{1}$, Е.В. Родионова ${ }^{1,}$, Е.А. Родин ${ }^{1}$, Н.А. Поклонский ${ }^{2}$, И.И. Аникеев ${ }^{2}$, С.В. Раткевич ${ }^{2}$ \\ ${ }^{1}$ Национальный исследовательский Мордовский государственный университет, \\ Саранск, Россия \\ ${ }^{2}$ Белорусский государственный университет, \\ Минск, Республика Беларусь \\ ฯ E-mail: Rodionova_j87@mail.ru
}

Поступила в Редакцию 9 сентября 2021 г.

В окончательной редакции 1 ноября 2021 г.

Принята к публикации 1 ноября 2021 г.

На примерах коротких открытых углеродных нанотрубок типа armchair $(n, n)$, для $n=3$, 4, и zigzag $(n, 0)$, для $n=5,6,7$, изучено влияние величины и направления вектора напряженности внешнего постоянного электрического поля на их автоэмиссионные свойства. Показано, что отклонение вектора напряженности поля от оси нанотрубки приводит к увеличению напряженности поля для генерации автоэмиссии электронов. Образующиеся в результате нового типа сопряжения р-электронов в цилиндрических сопряженных системах эмиссионные орбитали в углеродных нанотрубках $(n, n)$ более чувствительны к изменению направления вектора напряженности электрического поля по сравнению с эмиссионными орбиталями в нанотрубках $(n, 0)$. При отклонении вектора напряженности электрического поля от оси нанотрубки эмиссионные орбитали углеродных нанотрубок изменяются тем меньше, чем больше диаметр нанотрубки.

Ключевые слова: короткие открытые углеродные нанотрубки, автоэлектронная эмиссия, сопряжение $p$-электронов, эмиссионная молекулярная орбиталь.

DOI: 10.21883/FTT.2022.03.52097.201

\section{1. Введение}

Автоэмиссионные катоды на основе одностенных углеродных нанотрубок (УНТ) обладают рядом преимуществ перед прочими острийными катодами $[1,2]:$ высокая плотность эмиссионного тока, низкое отпирающее напряжение, высокая температура плавления, устойчивость к радиационным воздействиям. Широкое использование углеродных нанотрубок в микроэлектровакуумной электронике в значительной степени обусловливается морфологией катодного материала, которая определяется методом его синтеза и последующей обработкой получаемых массивов УНТ. Экспериментально показано [2], что пространственно структурированные УНТ в виде „леса“ проявляют лучшие эмиссионные свойства, чем УНТ, уложенные хаотично. Однако теоретические исследования влияния морфологии УНТ в катодном материале на их эмиссионные свойства носят отрывочный характер $[3,4]$ и не содержат результатов, которые можно считать рекомендациями для практического использования. Это положение во многом определяется отсутствием принятой концепции, связывающей электронное строение углеродных нанотрубок и их эмиссионные свойства. Таким образом, исследования в области прогнозирования эмиссионных свойств индивидуальных нанотрубок и массивов из них остаются актуальными [5].

Большинство работ, посвященных как теоретическому моделированию полевой эмиссии электронов, так и интерпретации экспериментальных данных, используют теорию Фаулера-Нордгейма (ФН) [6]. Обычно классическая теория ФН адаптируется для УНТ путем введения различных подгоночных коэффициентов [3]. В работах $[7,8]$ представлено новое дополнение теории $\Phi Н$, которое позволяет учитывать влияние реальных особенностей строения нанотрубок, а именно: наличие крышек на торцах УНТ, собственных дефектов, примесных атомов или функциональных групп - на эмиссионные свойства УНТ.

Согласно современным представлениям об электронном сопряжении в сферических и цилиндрических молекулах [9-13], в одностенных углеродных нанотрубках реализуется особый тип сопряжения $p$-электронов in-plane электронное сопряжение. В отличие от классического $\pi$-электронного сопряжения, in-plane электронное сопряжение в сферических и цилиндрических углеродных макромолекулах обеспечивает такую ориентацию $p$-орбиталей относительно углеродного остова, которая обусловливает повышенную электронную плотность внутри молекулы. Для минимизации полной энергии молекул с in-plane электронным сопряжением происходит „выталкивание“ электронной плотности из внутренней полости нанотрубки, приводя к формированию новых особых молекулярных состояний - эмиссионных молекулярных орбиталей (ЭМО, ЕМО) [7,8]. Иными словами, формирование ЭМО вследствие кривизны поверхности однослойных углеродных нанотру- 
бок представляет собой перераспределение плотности $p$-электронов из внутренней области УНТ наружу на их внешнюю поверхность [14]. Подобное перераспределение плотности $p$-электронов (с вогнутой стороны на выпуклую) имеет место и при изгибе графенового листа [15]. Таким образом, кристаллографические предпосылки для образования ЭМО имеет также боковая поверхность УНТ.

Характерной особенностью ЭМО углеродных нанотрубок является преимущественная локализация электронной плотности вблизи торцевых поверхностей цилиндрической молекулы. В [16] показано, что протяженность области преимущественной локализации электронной плотности в УНТ составляет 4-5.5 А, отсчитывая от края нанотрубки. Образующиеся эмиссионные молекулярные орбитали являются вакантными [7], их заселенность будет определяться только температурой и поэтому иметь незначительную величину. Это обстоятельство обусловливает низкие значения плотности тока автоэмиссии при малых значениях напряженности электрического поля [17]. В то же время такое состояние ЭМО может служить физической основой для интерпретации эмиссии электронов из массивов УНТ под действием интенсивного видимого света [18].

В [7] показано, что однородное постоянное электрическое поле, силовые линии которого параллельны оси УНТ, вызывает изменение энергии ЭМО, приводящее к перемещению эмиссионных молекулярных орбиталей в валентную зону (т.е. в область занятых электронами молекулярных орбиталей). При некоторой критической величине напряженности электрического поля происходит заполнение ЭМО электронами валентной зоны, что и является физической основой резкого увеличения плотности тока холодной полевой эмиссии [17] благодаря туннелированию электронов ЭМО через потенциальный барьер в соответствии с теорией $Ф \mathrm{H}[3,6]$.

Представленный механизм полевой эмиссии из УНТ был успешно апробирован на примере ультракоротких УНТ в электрическом поле при параллельной ориентации вектора напряженности поля и оси нанотрубок [7]. Различные методы синтеза УНТ порождают материалы с различной морфологией расположения нанотрубок $[2,19,20]$. Кроме того, для различных устройств формы электродов могут широко варьироваться, и, следовательно, силовые линии электрического поля могут быть направлены под различными углами к оси нанотрубок. Цель данной работы - исследование влияния направления и величины вектора напряженности внешнего постоянного электрического поля на энергии эмиссионных молекулярных орбиталей в углеродных нанотрубках $(3,3)$ и $(5,0)$.

\section{2. Модель и метод расчета}

В данной работе в качестве объектов исследования были выбраны ультракороткие открытые однослойные (одностенные) углеродные нанотрубки хирально-

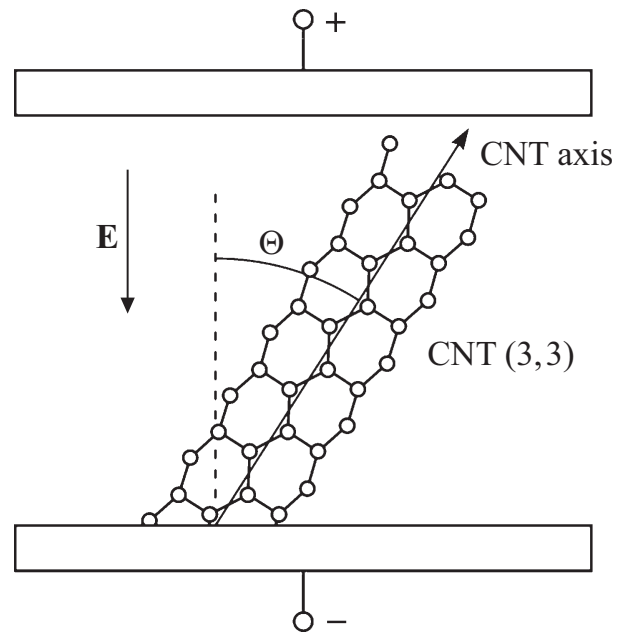

Рис. 1. Направление вектора напряженности внешнего однородного стационарного электрического поля $\mathbf{E}$ к оси углеродной нанотрубки $(3,3)$.

сти $(n, 0)$, где $n=5,6,7$ и $(n, n)$, где $n=3$, 4. Закрытые УНТ в данной работе не исследовались, так как их эмиссионные свойства значительно уступают свойствам открытых нанотрубок [7]. Протяженность модельных УНТ составила 6 циклических транс- и цис-углеродных цепочек, образующих цилиндрический углеродный остов. Свободные валентности концевых атомов углерода в нанотрубках насыщались атомами водорода.

Пространственная структура модельных УНТ определялась оптимизацией в рамках метода Хартри-Фока в базисе 3-21G из пакета прикладных программ FireFly [21], далее вычислялись энергетические спектры этих УНТ.

Влияние однородного постоянного электрического поля на энергетический спектр рассматриваемых модельных УНТ численно моделировалось с помощью опции EFIELD [21]. Величина напряженности $E$ постоянного электрического поля изменялась в пределах $0-21 \mathrm{~V} / \mathrm{nm}$ с шагом в $1 \mathrm{~V} / \mathrm{nm}$. Вектор напряженности постоянного электрического поля был направлен под углом $\Theta$ относительно оси нанотрубки (рис. 1). Угол $\Theta$ изменялся от $0^{\circ}$ (вектор напряженности поля направлен по оси УНТ) до $90^{\circ}$ (вектор напряженности направлен перпендикулярно оси УНТ) с шагом $15^{\circ}$.

\section{3. Обсуждение результатов}

В энергетическом спектре углеродных нанотрубок присутствуют несколько групп эмиссионных орбиталей, различающихся числом узлов $L$ инверсии знака атомных волновых функций в базисном разложении ЭМО (см. рис. 2). Первая группа (I) эмиссионных орбиталей представлена двумя вырожденными по энергии вакантными (молекулярными орбиталями) $\mathrm{MO}$ с $L=2$. Вторая группа (II) состоит из четырех вырожденных по энергии 


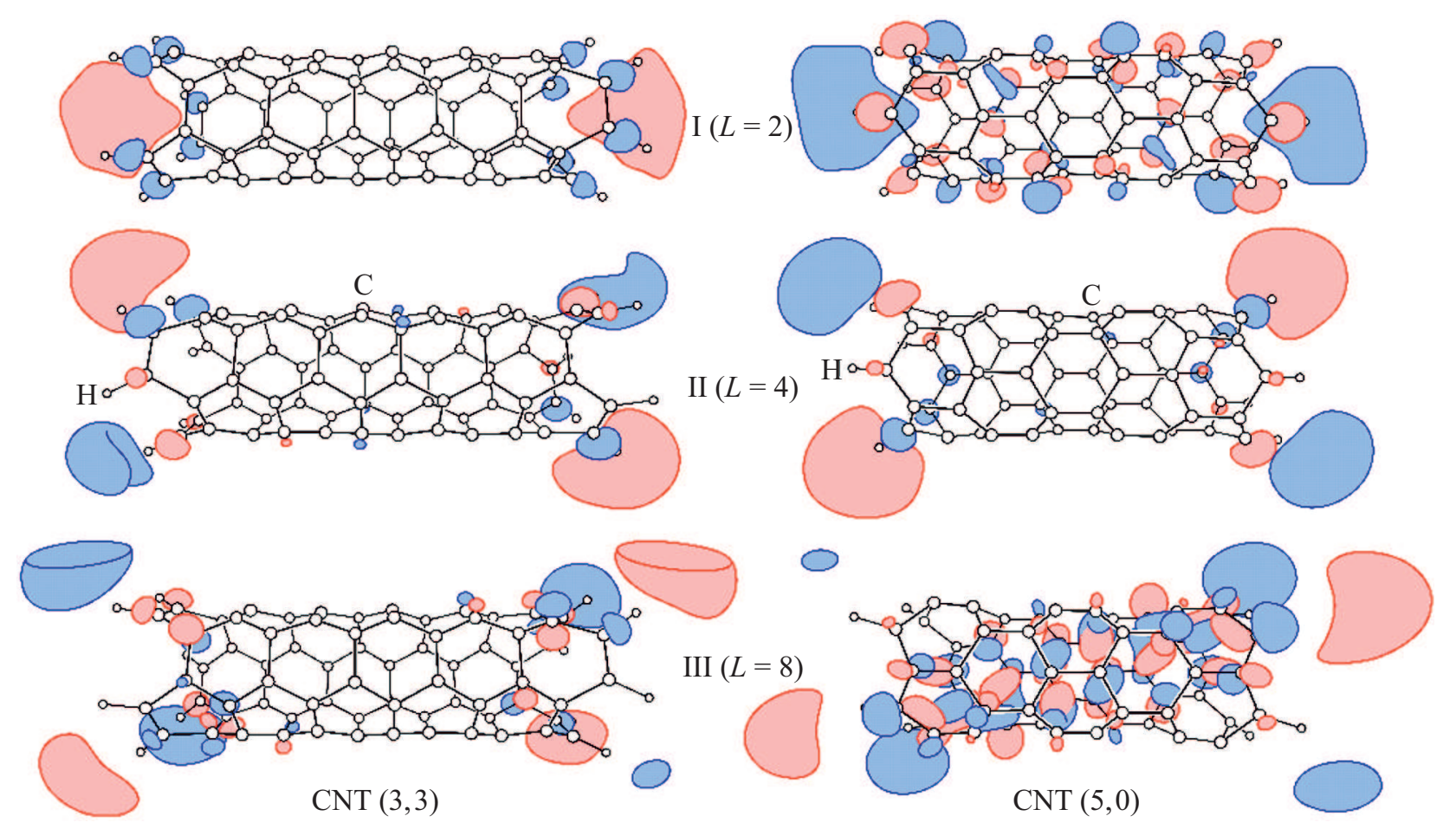

Рис. 2. Структура эмиссионных молекулярных орбиталей в УНТ $(3,3)$ и $(5,0)$.

вакантных МО с $L=4$. Энергия ЭМО увеличивается с ростом числа $L$. Поэтому эмиссионные орбитали третьей группы (III) с $L=8$ лежат глубоко в валентной зоне и существенно не влияют на эмиссионные свойства УНТ в обозначенном интервале напряженностей электрического поля.

На рис. 3 представлены зависимости энергии граничных (верхней заполненной электронами - НОМО и нижней вакантной - LUMO) и эмиссионных (ЭМO) молекулярных орбиталей модельных углеродных нанотрубок $(3,3)$ и $(5,0)$ от величины напряженности $E$ постоянного электрического поля, вектор напряженности которого направлен под углом $\Theta$ к оси УНТ.

В случае $\Theta=0^{\circ}$ приложенное электрическое поле оказывает наибольшее влияние на энергии эмиссионных орбиталей $\left(\varepsilon_{\mathrm{EMO}}\right)$, тогда как энергии НОМО ( $\left.\varepsilon_{\mathrm{HOMO}}\right)$ и LUMO ( $\left.\varepsilon_{\text {LUMO }}\right)$ орбиталей изменяются в меньшей степени. Рассмотрим поведение ЭМО в электрическом поле на примере эмиссионных орбиталей с $L=2$. В электрическом поле в соответствии с эффектом Штарка [11-13] происходит расщепление вырожденных по энергии эмиссионных орбиталей ЭМО Энергия одной из эмиссионных орбиталей ЭМО 1 уменьшается, и при некотором значении напряженности поля величина энергии ЭМО достигает величины энергии LUMO, а затем, при $E=E_{\mathrm{cr}}^{\mathrm{I}}-$ величины энергии НОМО. Энергия второй эмиссионной орбитали ЭМО при увеличении напряженности электрического поля значительно увеличивается и не представляет интереса при описании эмиссионных свойств УНТ. Поведение эмиссионных орбиталей с $L=4$ аналогично поведению
ЭМО с $L=2$. Так, при напряженности электрического поля $E_{\mathrm{cr}}^{\mathrm{II}}$ величина энергии ЭМО с $L=4$ достигает величины энергии НОМО. Это обстоятельство качественно объясняет увеличение тока эмиссии с увеличением напряженности приложенного поля [3-5].

При отклонении вектора напряженности электрического поля от оси нанотрубки закономерности поведения энергии граничных орбиталей и ЭМО 1 при увеличении напряженности поля сохраняются (рис. 3), а величина расщепления ЭМО будет уменьшаться. Вырождение ЭМО полностью сохраняется при $\Theta=90^{\circ}$ благодаря равнозначности ЭМО при указанном направлении электрического поля и уменьшению дипольного момента УНТ.

Проследим влияние величины $\Theta$ на критические значения напряженности внешнего электрического поля $\left(E_{\mathrm{cr}}^{\mathrm{I}}\right.$ и $\left.E_{\mathrm{cr}}^{\mathrm{II}}\right)$. Из таблицы видно, что критические значения напряженности поля, обеспечивающие автоэмиссию электронов, при сравнимых радиусах для УНТ типа armchair меньше, чем в случае УНТ типа zigzag, что соответствует данным [22].

Для всех рассмотренных модельных УНТ при увеличении угла $\Theta$ наблюдается смещение области автоэмиссии электронов в сторону более сильных полей. При $\Theta=90^{\circ}$ в диапазоне электрических полей до $20 \mathrm{~V} / \mathrm{nm}$ не наблюдается переход ЭМО в валентную зону. В отличие от УНТ хиральности $(n, 0)$, эмиссионные свойства модельных нанотрубок хиральности $(n, n)$ оказались более чувствительны к направлению вектора напряженности электрического поля относительно оси УНТ. Так, величины критических напряженностей поля, 

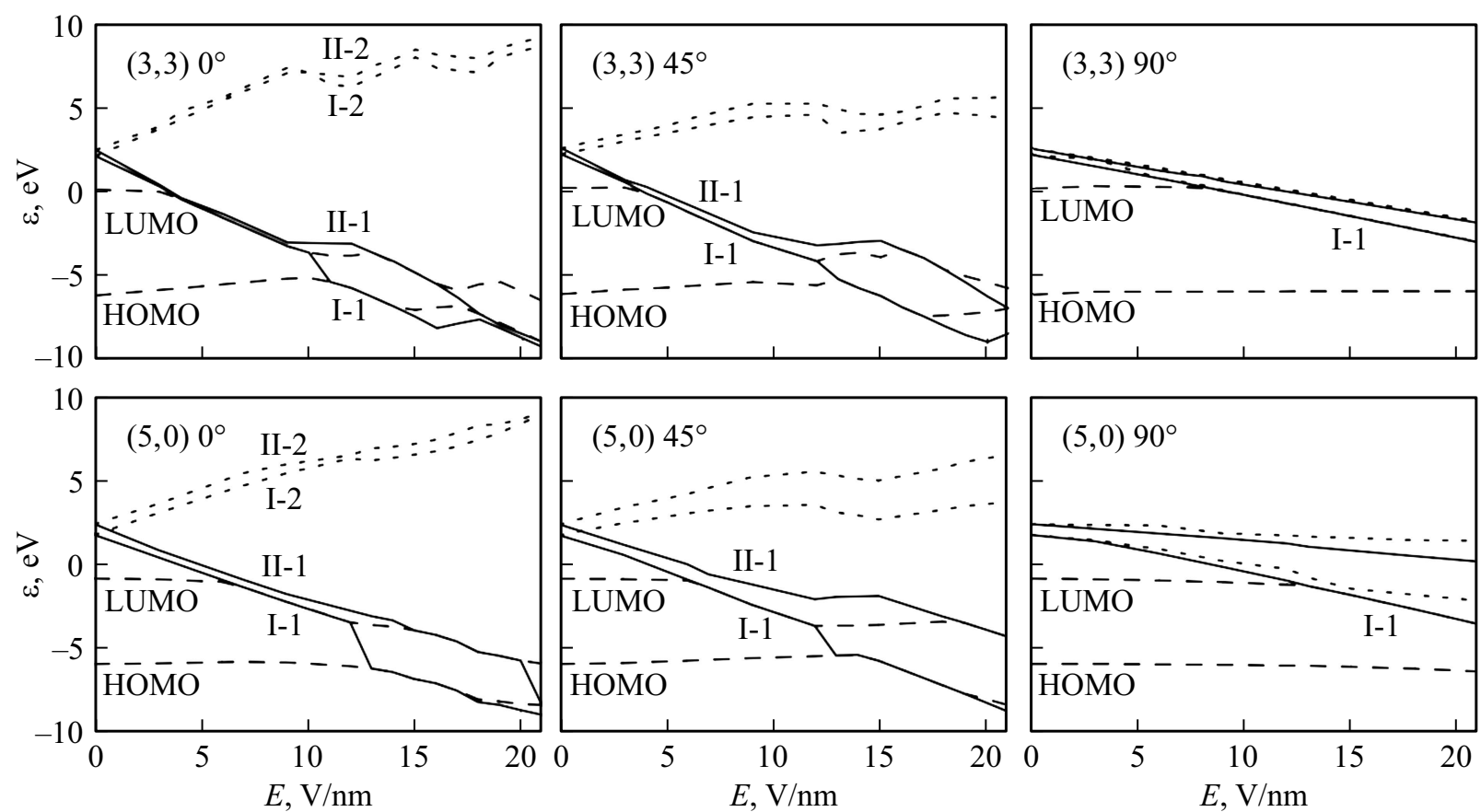

Рис. 3. Зависимость энергий граничных (НОMO и LUMO) и эмиссионных (I-1(2) - ЭМО I-1(2), II-1(2) - ЭМО II-1(2) $)$ молекулярных орбиталей УНТ $(3,3)$ и $(5,0)$ от величины напряженности $E$ внешнего электрического поля при $\Theta=0^{\circ}, 45^{\circ}$ и $90^{\circ}$.

обеспечивающие заполнение ЭМО $(L=2)$ электронами, для УНТ $(n, 0)$ начинают увеличиваться при $\Theta=60^{\circ}$, тогда как $E_{\mathrm{cr}}^{\mathrm{I}}$ УНТ $(n, n)$ имеют тенденцию к увеличению уже при $\Theta=45^{\circ}$. Полученные результаты находятся в соответствии с данными по зависимости коэффициента усиления электрического поля на конце УНТ от направления вектора напряженности поля, определенного в работе [23]. Увеличение диаметра модельных нанотрубок влияет на величины $E_{\text {cr }}$ в меньшей степени. Так, при $\Theta>60^{\circ}$ наблюдается „выравнивание“ эмиссионных свойств нанотрубок различных хиральностей и диаметров. Кроме того, увеличение диаметра УНТ типа zigzag уменьшает количество эмиссионных орбиталей в валентной зоне, что приводит к уменьшению тока эмиссии.

Перераспределение электронной плотности между молекулярными орбиталями с учетом ЭМО, образованных новым типом сопряжения $p$-электронов в цилиндрических молекулах, можно рассмотреть, исследуя дипольный момент $\boldsymbol{\mu}$ УНТ, возникающий под действием электрического поля. Вектор наведенного в электрическом поле дипольного момента можно разложить на проекции по осям $x$ (вдоль оси нанотрубки) и $y$ (поперек оси нанотрубки). Проекция $\mu_{x}$ дипольного момента $\boldsymbol{\mu}$ на ось $x$ характеризует продольную поляризуемость УНТ,

Величины критических напряженностей электрического поля, обеспечивающие переход эмиссионных орбиталей в LUMO и НОМО, для модельных УНТ $(n, 0)$ и $(n, n)$ в зависимости от угла $\Theta$

\begin{tabular}{|c|c|c|c|c|c|c|c|c|c|c|}
\hline & \multicolumn{10}{|c|}{ Индекс хиральности УНТ } \\
\hline & \multicolumn{2}{|c|}{$(5,0)$} & \multicolumn{2}{|c|}{$(6,0)$} & \multicolumn{2}{|c|}{$(7,0)$} & \multicolumn{2}{|c|}{$(3,3)$} & \multicolumn{2}{|c|}{$(4,4)$} \\
\hline Радиус, nm & \multicolumn{2}{|c|}{0.196} & \multicolumn{2}{|c|}{0.235} & \multicolumn{2}{|c|}{0.274} & \multicolumn{2}{|c|}{0.203} & \multicolumn{2}{|c|}{0.271} \\
\hline $\begin{array}{c}\text { Угол } \Theta, \\
\text { deg }\end{array}$ & $\begin{array}{c}E_{\mathrm{cr}}^{\mathrm{I}}, \\
\mathrm{V} / \mathrm{nm}\end{array}$ & $\begin{array}{c}E_{\mathrm{cr}}^{\mathrm{II}}, \\
\mathrm{V} / \mathrm{nm}\end{array}$ & $\begin{array}{c}E_{\mathrm{cr}}^{\mathrm{I}}, \\
\mathrm{V} / \mathrm{nm}\end{array}$ & $\begin{array}{c}E_{\mathrm{cr}}^{\mathrm{II}}, \\
\mathrm{V} / \mathrm{nm}\end{array}$ & $\begin{array}{c}E_{\mathrm{cr}}^{\mathrm{I}}, \\
\mathrm{V} / \mathrm{nm}\end{array}$ & $\begin{array}{c}E_{\mathrm{cr}}^{\mathrm{II}}, \\
\mathrm{V} / \mathrm{nm}\end{array}$ & $\begin{array}{c}E_{\mathrm{cr}}^{\mathrm{I}}, \\
\mathrm{V} / \mathrm{nm}\end{array}$ & $\begin{array}{c}E_{\mathrm{cr}}^{\mathrm{II}}, \\
\mathrm{V} / \mathrm{nm}\end{array}$ & $\begin{array}{c}E_{\mathrm{cr}}^{\mathrm{I}}, \\
\mathrm{V} / \mathrm{nm}\end{array}$ & $\begin{array}{c}E_{\mathrm{cr}}^{\mathrm{II}}, \\
\mathrm{V} / \mathrm{nm}\end{array}$ \\
\hline 0 & 13 & 21 & 18 & - & 20 & - & 11 & 18 & 11 & 18 \\
\hline 15 & 13 & 21 & 18 & - & 20 & - & 11 & 18 & 11 & 18 \\
\hline 30 & 13 & - & 18 & - & 20 & - & 11 & 19 & 11 & 19 \\
\hline 45 & 13 & - & 18 & - & 20 & - & 13 & 21 & 12 & 21 \\
\hline 60 & 15 & - & 20 & - & 21 & - & 15 & - & 14 & - \\
\hline 75 & 19 & - & 21 & - & 21 & - & 18 & - & 18 & - \\
\hline 90 & - & - & - & - & - & - & - & - & - & - \\
\hline
\end{tabular}



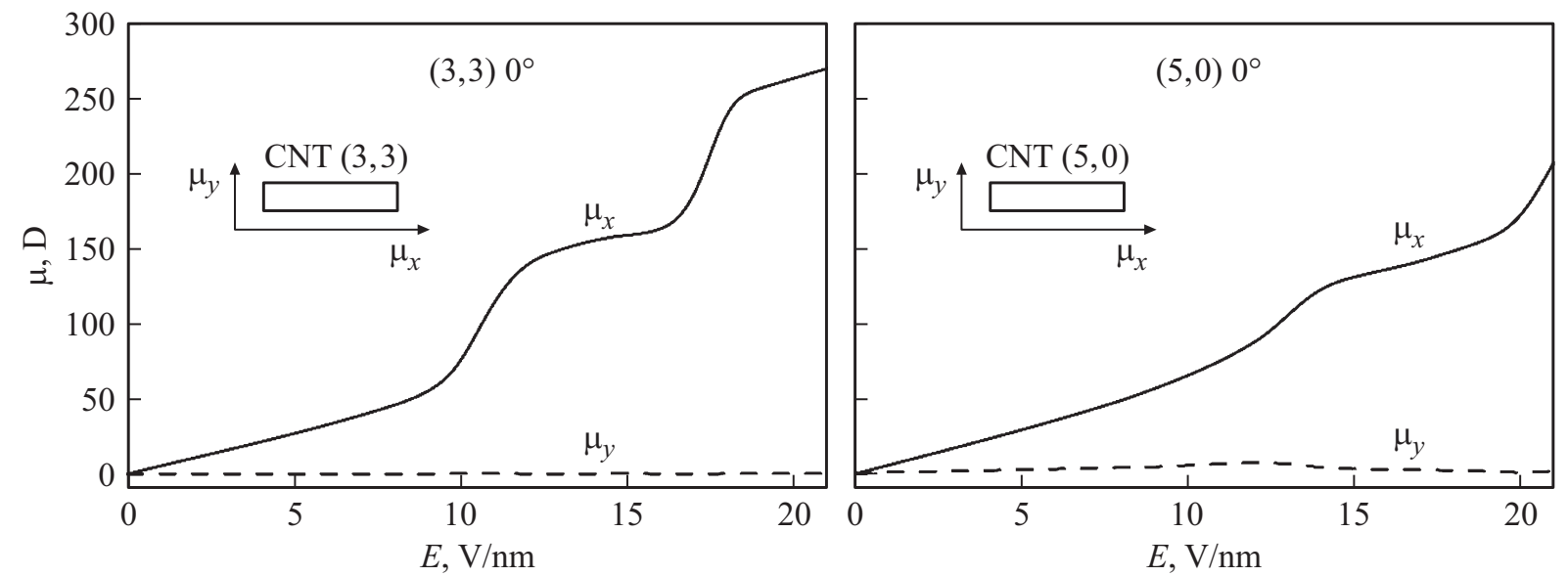

Рис. 4. Зависимость проекций $\mu_{x}$ и $\mu_{y}$ наведенного дипольного момента УНТ $(3,3)$ и $(5,0)$ от напряженности $E$ внешнего электрического поля (при $\Theta=0^{\circ}$ ). Величина дипольного момента приведена в дебаях; $1 \mathrm{D}=3.34 \cdot 10^{-30} \mathrm{C} \cdot \mathrm{m}$.
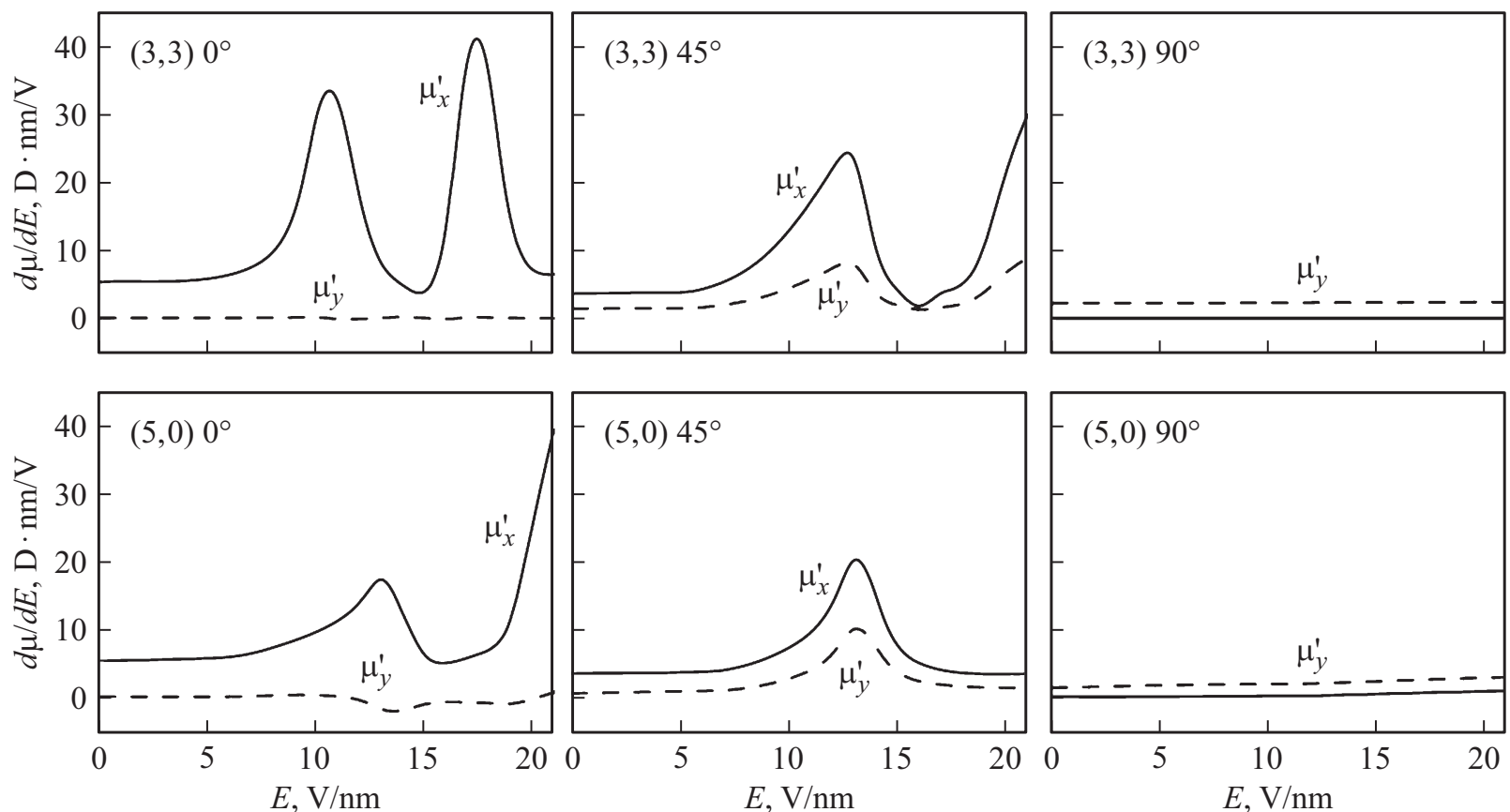

Рис. 5. Зависимости производных проекций дипольного момента УНТ $(3,3)$ и $(5,0)$ от напряженности $E$ внешнего электрического поля.

а проекция $\mu_{y}$ на ось $y-$ поперечную поляризуемость (рис. 4).

O существенном перераспределении электронной плотности УНТ в электрическом поле свидетельствует немонотонный рост дипольного момента при увеличении напряженности электрического поля. При $\Theta=0^{\circ}$ основной вклад в общий дипольный момент УНТ вносит его „продольная“ проекция $\mu_{x}$. Увеличение напряженности внешнего электрического поля приводит к росту величины дипольного момента.

На рис. 5 показаны зависимости производной дипольного момента по напряженности поля $d \boldsymbol{\mu} / d \mathbf{E}=\boldsymbol{\mu}^{\prime}$ от напряженности поля Е. Анализ этих зависимостей пока- зывает, что максимумы $\boldsymbol{\mu}^{\prime}$ соответствуют дополнительному, происходящему сверх обычной поляризуемости, перераспределению зарядов в УНТ. Так, для УНТ $(3,3)$, ориентированной по направлению внешнего электрического поля (при $\Theta=0^{\circ}$ ), максимум при $E=11 \mathrm{~V} / \mathrm{nm}$ соответствует переходу эмиссионной молекулярной орбитали $(L=2)$ в край валентной зоны, заполнению данной ЭМО электронами и, следовательно, накоплению электронной плотности в концевой области нанотрубки. Второй максимум связан с переходом следующей ЭМО $(L=4)$ в край валентной зоны при $E=18 \mathrm{~V} / \mathrm{nm}$. Аналогичные трансформации энергии ЭМО $(L=2$ и $L=4)$ в энергетическом спектре УНТ $(5,0)$ также 
приводят к возникновению максимумов при $E=E_{\mathrm{cr}}^{\mathrm{I}}$ и $E=E_{\mathrm{cr}}^{\mathrm{II}}$.

По мере увеличения угла $\Theta$ вклад „поперечной“ проекции дипольного момента $\mu_{y}$ в общий дипольный момент увеличивается. В то же время дипольный момент УНТ при заданной напряженности поля уменьшается при увеличении угла $\Theta$, практически исчезая при $\Theta=90^{\circ}$.

\section{4. Заключение}

Эмиссионные характеристики катодов на основе углеродных нанотрубок существенно зависят от морфологии используемых материалов. Так, при формировании больших по площади катодов методами печатных технологий образующиеся покрытия отличаются крайне низкой упорядоченностью УНТ [4,20]. Для изготовления таких катодов можно использовать нанотрубки любой хиральности и диаметра, так как эмиссионные свойства УНТ в массивах с низкой степенью упорядоченности „усредняются“".

В то же время, массивы с высокой степенью упорядоченности УНТ, получаемые по технологии „леса“ [2], предпочтительно формировать из нанотрубок типа armchair, так как для них величина критической напряженности поля появления холодной эмиссии электронов $\left(E_{\mathrm{cr}}^{\mathrm{I}}\right)$ меньше, чем для массивов УНТ типа zigzag при сравнимых радиусах нанотрубок. Кроме того, катоды из нанотрубок типа armchair имеют устойчивые эмиссионные характеристики независимо от радиуса применяемых УНТ.

\section{Конфликт интересов}

Авторы заявляют об отсутствии конфликта интересов.

\section{Финансирование работы}

Работа поддержана государственной программой научных исследований Республики Беларусь „Конвергенция-2025“"

\section{Список литературы}

[1] И.Д. Евсиков, С.В. Митько, П.Ю. Глаголев, Н.А. Дюжев, Г.Д. Демин. ЖТФ 90, 11, 1931 (2020).

[2] Э.Г. Раков. Успехи химии 82, 6, 538 (2013).

[3] А.В. Елецкий. УФН 180, 9, 897 (2010).

[4] F. Giubileo, A. Bartolomeo, L. Iemmo, G. Luongo, F. Urban. Appl. Sci. 8, 4, 526 (2018).

[5] Е.Д. Эйдельман, А.В. Архипов. УФН 190, 7, 693 (2020).

[6] S. Parveen, A. Kumar, S. Husain, M. Husain. Physica B 505, 1 (2017).

[7] О.Б. Томилин, Е.В. Родионова, Е.А. Родин. Журн. физ. химии 94, 8, 1242 (2020).

[8] О.Б. Томилин, Е.В. Родионова, Е.А. Родин. Журн. физ. химии 95, 9, 1396 (2021).
[9] P. von Ragué Schleyer, H. Jiao, M.N. Glukhovtsev, J. Chandrasekhar, E. Kraka. J. Am. Chem. Soc. 116, 22, 10129 (1994).

[10] A.A. Fokin, H. Jiao, P. von Ragué Schleyer. J. Am. Chem. Soc. 120, 36, 9364 (1998).

[11] А.В. Тучин, Л.А. Битюцкая, Е.Н. Бормонтов. Нано- и микросистемная техника 4, 19 (2013).

[12] А.В. Тучин, Л.А. Битюцкая, Е.Н. Бормонтов. ФТТ 56, 8, 1632 (2014).

[13] R.I. Gearba, T. Mills, J. Morris, R. Pindak, C.T. Black, X. Zhu. Adv. Funct. Mater. 21, 14, 2666 (2011).

[14] T. Dumitrica, Ch.M. Landis, B.I. Yakobson. Chem. Phys. Lett. 360, 1-2, 182 (2002).

[15] N.A. Poklonski, S.V. Ratkevich, S.A. Vyrko, A.T. Vlassov. Int. J. Nanosci. 18, 03n04, 1940008 (2019).

[16] О.Б. Томилин, Н.А. Поклонский, Е.В. Родионова, Е.А. Родин, И.И. Аникеев, В.А. Кушнеров, А.С. Читалов. Материалы и структуры современной электроники. Материалы IX Междунар. науч. конф. (14-16 октября 2020 г.) БГУ, Минск (2020). 406 с.

[17] S. Han, J. Ihm. Phys. Rev. B 66, 24, 241402(R) (2002).

[18] P. Yaghoobi, M.V. Moghaddam, A. Nojeh. In: 23rd Int. Vacuum Nanoelectronic Conf. Palo Alto, CA (2010). P. 8.2.115

[19] A. Navitski, G. Müller, V. Sakharuk, A.L. Prudnikava, B.G. Shulitski, V.A. Labunov. J. Vac. Sci. Technol. 28, 2, C2B14 (2010).

[20] J.W. Song, Y.S. Kim, Y.H. Yoon, E.S. Lee, C.S. Han, Y. Cho, D. Kim, J. Kim, N. Lee, Y.G. Ko, H.T. Jung, S.H. Kim. Physica E 41, 8, 1513 (2009).

[21] M.W. Schmidt, K.K. Baldridge, J.A. Boatz, S.T. Elbert, M.S. Gordon, J.H. Jensen, S. Koseki, N. Matsunaga, K.A. Nguyen, S.J. Su, T.L. Windus, M. Dupuis, J.A. Montgomery. J. Comp. Chem. 14, 11, 1347 (1993).

[22] A.G. Rinzler, J.H. Hafner, P. Nikolaev, P. Nordlander, D.T. Colbert, R.E. Smalley, L. Lou, S.G. Kim, D. Tománek. Sci. 269, 5230, 1550 (1995).

[23] М.Д. Бельский, Г.С. Бочаров, А.В. Елецкий, Т.J. Sommerer. ЖТФ 80, 2, 130 (2010).

Редактор Е.В. Толстякова 